\title{
AMÉRICA LATINA SEGÚN WHITNEY Y DISNEY. EL CINE INTERAMERICANO DE LA POLÍTICA DE BUENA VECINDAD EN LOS AÑOS 1930 Y 40
}

\author{
ANDRÁs LÉNÁRT
}

Universidad de Szeged

\begin{abstract}
Resumen: La representación de otras naciones en el cine estadounidense se ha adherido siempre a las líneas generales de la política exterior del país. En cuanto a América Latina -a lo largo del siglo XX-, la aparición de los latinos en el cine de Hollywood también dependía de las relaciones diplomáticas vigentes entre las dos regiones. En mi artículo presento los aspectos cinematográficos de la nueva actitud de los EE. UU. hacia América Latina en los años 30 y la primera mitad de los 40, dentro del marco de la Política de Buena Vecindad, formulada por el presidente Franklin Delano Roosevelt. En esta misión tenía un papel clave John Hay Whitney, director de la División Cinematográfica de una oficina especializada (OIAA), contando con el apoyo de varios cineastas famosos, entre otros, Walt Disney.
\end{abstract}

Palabras clave: Política de Buena Vecindad, cine interamericano, estereotipos, John Hay Whitney, Walt Disney

\begin{abstract}
The representation of other nations in American cinema has always fallen in line with the guiding principles of the country's foreign policy. As for Latin America -throughout the 20th century- the emergence of latinos in Hollywood cinema also depended on the current diplomatic relations between the two regions. In my article I present the cinematographic aspects of the USA's new attitude towards Latin America in the 1930s and the first half of the 1940s, within the framework of the Good Neighbor Policy, formulated by President Franklin Delano Roosevelt. In this mission John Hay Whitney, director of the Motion Picture Division of a specialized office (OIAA), had a key role, with the support of several famous filmmakers, among others, Walt Disney.
\end{abstract}

Keywords: Good Neighbor Policy, Inter-American Cinema, stereotypes, John Hay Whitney, Walt Disney

Según las investigaciones del historiador John Henry Coatsworth, entre el año 1898 (la guerra hispano-estadounidense) y el comienzo del siglo XXI los Estados Unidos de América intervino con éxito en 41 cambios de gobierno en América Latina (sin incluir los intentos fracasados): 17 veces recurrió a la actuación directa y 24 veces se valió de la intromisión indirecta (Coatsworth, 2005). El punto de partida fue la Doctrina Monroe, presentada en 1823 dentro del marco del 
América Latina según Whitney y Disney. El cine interamericano de la Política de Buena Vecindad en los años 1930 y 40

aislacionismo estadounidense: según esta doctrina, proclamando el principio de "América es para los americanos", cualquier futura intervención de los estados europeos en la vida del continente americano sería inaceptable. Los Estados Unidos garantizaría la seguridad y la paz en el Nuevo Mundo. Desde este momento, la influencia política, económica, cultural y militar de los EE. UU. se iba reforzando en todo el hemisferio. El ideario del Destino Manifiesto y los corolarios agregados a la Doctrina Monroe impulsaron la hegemonía de este país sobre América Latina y el Caribe, esgrimiendo argumentos como la expansión vital de la civilización y la prevención de los posibles peligros que podrían llegar desde fuera. Al entrar en la Primera Guerra Mundial en 1917, el principio del aislacionismo se quedó suspendido provisionalmente y, aunque en el periodo de entreguerras el país volvería a retirarse al segundo plano, desde la Segunda Guerra Mundial estaría presente como una superpotencia indispensable.

\section{El nacimiento de la Política de Buena Vecindad}

En los años 30, en sintonía con la transformación de la situación internacional, el protagonismo de la Doctrina Monroe iba menguando, y en 1933 el presidente Franklin Delano Roosevelt anunció la Política de Buena Vecindad. El objetivo fue la cristalización de una solidaridad panamericana contra las amenazas exteriores, teniendo en cuenta los procesos político-sociales que se llevaban a cabo en esta década en Europa. En los años que precedían la Segunda Guerra Mundial, para los EE.UU estaba claro que pronto necesitaría varios aliados y parecía que sus vecinos pudieran ser los colaboradores naturales. Igualmente, había que prevenir que el fascismo y el nazismo, cada vez más populares en la Europa de los 30, tuvieran seguidores entre los gobiernos de América Latina. Durante la guerra, las naciones latinoamericanas suponían un apoyo imprescindible para los EE. UU., en algunos países (como Nicaragua o Guatemala) incluso fueron instauradas dictaduras derechistas que simpatizaban con el coloso del norte. Un elemento trascendental de esta política fue la derogación en 1934 de la Enmienda Platt, el apéndice que el vecino del norte había añadido a la constitución de Cuba en 1901 con el fin de restringir la independencia de los cubanos. Además, este mismo año, la tropas estadounidenses dejaron Haití, ocupada en 1915 por el presidente Woodrow Wilson ante el temor de que los intereses europeos disminuyeran la influencia de los Estados Unidos tanto en ese país como en toda la región del Caribe (Danticat, 2015:9-10). 
Roosevelt procuró sustituir el intervencionismo estadounidense con una llamada a la colaboración entre todas las naciones de América. El 4 de marzo de 1933 el trigésimo segundo presidente de los Estados Unidos de América proclamó en su discurso inaugural:

En el campo de la política mundial, dedicaría esta nación a la política del buen vecino -el vecino que respeta a sí mismo y, porque lo hace, respeta los derechos de los otros-, el vecino que respeta sus obligaciones y respeta la santidad de sus acuerdos en y con un mundo de vecinos (Moral Roncal, 2003:23).

Esta nueva actitud era incompatible con el empleo de la fuerza militar en América Latina y en el Caribe. Tanto él como los miembros de su gobierno acentuaron en sus discursos que la Casa Blanca renunció a la intervención armada en esta región. Para subrayar esta postura, el gobierno estadounidense firmó dos acuerdos en 1933, uno en Montevideo y otro en Buenos Aires, en los que declaró: "[...] ningún país tiene el derecho de intervenir directa o indirectamente en los asuntos internos o externos de otro" (Selser, 2001:597).

La nueva concepción estadounidense acerca de América Latina conllevó también un cambio a nivel social y cultural, porque la anulación de los estereotipos y prejuicios no pudo llevarse a cabo de un día al otro. Hacía falta efectuar una serie de reajustes en cuanto a la percepción de todos los países y pueblos del continente americano. Acto seguido, la diplomacia cultural obtuvo un papel crucial en esta misión, cuya esfera de acción, en este caso, incluía tanto la política interior como la exterior. Las investigaciones internacionales sobre la dimensión cultural de las relaciones entre los Estados Unidos y América Latina - llevadas a cabo en los archivos y filmotecas de los países americanos y en los de los estudios cinematográficos como Disney o RKO- han abierto nuevos acercamientos y posibilidades de análisis sobre las confluencias entre la política, la economía, la sociedad y la identidad cultural en estas regiones. Asimismo, constituye un componente fundamental del ámbito interdisciplinario de los estudios interamericanos. 
América Latina según Whitney y Disney. El cine interamericano de la Política de Buena Vecindad en los años 1930 y 40

\section{La política cinematográfica interamericana de Roosevelt y Whitney}

El presidente Roosevelt estableció en agosto de 1940 la Oficina para la Coordinación de Relaciones Comerciales y Culturales de las Repúblicas Americanas (Office for Coordination of Commercial and Cultural Relations Between the American Republics, OCCCRBAR) que en 1941 adoptó el nombre Oficina del Coordinador de Asuntos Interamericanos (Office of the Coordinator of Inter-American Affairs, $O C I A A)$ y, por fin, en 1945 pasó a llamarse Oficina de Asuntos Interamericanos (Office of Inter-American Affairs, OLAA). En la historiografía interamericana se utiliza esta última denominación con la mayor frecuencia, incluso si se hace referencia a las entidades predecesoras. La tarea principal de la OIAA fue oponerse a la influencia alemana e italiana en el continente americano y mejorar tanto la imagen de los EE. UU. en América Latina como al revés. La Oficina fue creada

[...] para ayudar en la preparación y coordinación de políticas que estabilicen las economías latinoamericanas, para asegurar y profundizar la influencia de Estados Unidos en la región, y para combatir las incursiones del Eje en el hemisferio, particularmente en las esferas comercial y cultural (Cramer - Prutsch, 2006:786).

El coordinador de la Oficina fue el filántropo y hombre de negocios Nelson A. Rockefeller. La esfera de acción de la OIAA abarcaba los terrenos del comercio, comunicación, prensa, radio, cine, educación, cultura y, como un elemento integrante de todas las actividades, la propaganda. Para alcanzar los objetivos, la Oficina contaba con la colaboración de los representantes más importantes e influyentes de estas áreas. En los países latinoamericanos sus filiales funcionaban bajo la supervisión de la embajadas estadounidenses y recibían el auspicio incondicional de aquellos ejecutivos de empresas que tenían negocios y una amplia red de relaciones en las regiones meta. La actividad de la OIAA ambicionaba controlar todas las esferas de la vida en las que existía alguna relación entre los estados americanos (Cramer-Prutsch, 2006). La labor cultural ocupaba un ingrediente egregio de la misión de esta organización mediante varios instrumentos; por ejemplo, incluía el nombramiento de embajadores de buena voluntad o la financiación de eventos y giras culturales en América Latina. Los cineastas Walt Disney, Orson Welles, Bing Crosby, John Ford y la compañía de danza Ballet Americano, entre otros, formaban parte del amplio abanico de colaboradores (Benamou, 2007:244-245). 
Una de la divisiones más notables de la OIAA fue la División Cinematográfica (Motion Picture Division), bajo la dirección de John Hay Whitney. El director emprendió un viaje para varios países latinoamericanos en busca de socios y promotores fiables con el fin de difundir las ideas democráticas entre el público de las Américas a través del cine, contrarrestando la influencia del nazismo. Las oficinas extranjeras de la División, ubicadas en las grandes ciudades latinoamericanas, exploraban las condiciones y posibilidades de esta nueva política cinematográfica dirigida desde los Estados Unidos. Los Comités de Coordinación, relacionados con esta misión, revisaban las películas exportadas a esta región e intentaban predecir qué temas podrían tener una buena acogida en estas sociedades. Hacía falta colaborar con los varios departamentos y ministerios de los países latinoamericanos, y también con las entidades de censura para evitar que las obras hirieran las sensibilidades de la nación y que, por consiguiente, el gobierno local impidiera la distribución de las obras. La División de la OIAA tenía que planificar todos los pasos y, a la vez, tomar precauciones para prevenir los posibles conflictos que podrían originarse del descuido del cineasta o de la productora cinematográfica. Aunque esta preparación minuciosa estaba vigente en todos los terrenos de la expansión de los medios de comunicación estadounidenses hacia América Latina, pero el cine suponía un factor destacado. Whitney elaboró el llamado Plan para estimular la producción cinematográfica de la Industria Mexicana en apoyo de los esfuerzos bélicos; la finalidad principal de este plan era desarrollar las industrias cinematográficas de los países latinoamericanos. México fue elegido como el lugar ideal para ensayar las prácticas. El país vecino tenía una industria cinematográfica de alto nivel y los dos gobiernos mantenían relaciones diplomáticas amistosas. Según el Plan rubricado por ambas partes en el año 1942, los objetivos eran coadyuvar la cinematografía mexicana en la producción de películas que servían los fines propagandísticos bélicos contra la influencia de los países del Eje y, de igual modo, establecer las condiciones adecuadas para que tal actividad pudiera realizarse también en otros países de la región. Según los historiadores, este acuerdo entre los EE.UU y México fue la razón principal por la que la industria fílmica de la Alemania nazi era incapaz de imponer su voluntad sobre el cine mexicano y, por consiguiente, sobre el cine hispanohablante de las Américas (Jarvinen - Peredo Castro, 2011:53-54; Rankin, 2009:90-93).

Desarrollar un nexo cultural-cinematográfico entre las varias regiones de América escondía en sí la promesa de conseguir los objetivos interamericanos en varios ámbitos. Al lado de perseguir una solución satisfactoria para acabar con la 
América Latina según Whitney y Disney. El cine interamericano de la Política de Buena Vecindad en los años 1930 y 40

mayor preocupación de la Casa Blanca en la época (neutralizar la expansión latinoamericana del nazismo y fascismo europeos), la "invasión" de las películas estadounidenses ofrecía la posibilidad de cosechar resultados más complejos de los que podrían sacar provecho a largo plazo. A través de las obras de Hollywood y la interpretación de las grandes estrellas de entonces, las sociedades latinoamericanas -que a menudo vivían entre condiciones económicas pésimas e incluso, en algunos casos, bajo un sistema político opresor- llegaron a conocer el llamado the American way of life, las costumbres y el estilo cotidiano de los Estados Unidos de América, un mundo tan lejano y, aparentemente, fabuloso. Estas películas presentaban una imagen sumamente positiva sobre el coloso del norte, un aliado natural a la hora de elegir entre él y los países europeos de la extrema derecha. Al mantener bajo control estadounidense el mercado cinematográfico de América Latina, el público se volvió "americanizado" en sus propias salas de cine. Acto seguido, dentro del marco de la nueva Política de Buena Vecindad, la imagen ideal formulada sobre los estadounidenses fue complementada con un nuevo acercamiento hacia los latinoamericanos. Este proyecto cinematográfico era adecuado para desempeñar un doble papel en la misión interamericana: por un lado, plasmar una imagen favorable en los latinoamericanos sobre los Estados Unidos; por otro lado, propagar la idea del interamericanismo y de la amistad y cooperación panamericana en su propio país.

\section{El cine interamericano de la buena vecindad}

La actividad de la División de Whitney fue la continuación de una tendencia que había empezado en la primera mitad de los años 30 para transformar los estereotipos que proyectaban las películas de Hollywood sobre los latinoamericanos. El cine estadounidense, aunque generalmente no tenía la intención de representar a los hispanos de manera ofensiva (con algunas excepciones), pero la imagen que transmitían sobre ellos era bastante superficial y unilateral, adecuada para ridiculizar a las sociedades latinoamericanas. La observación de los clichés modelados por los estadounidenses sobre la gente de las otras regiones de América proporcionó la materia prima para que varios artistas modelaran su trabajo creativo durante la fase de preparación antes de un rodaje. Según estas acepciones, la mayoría de los latinoamericanos eran vagos, violentos, impulsados solo por sus instintos básicos, su vida era guiada por sus tradiciones y por su pensamiento atrasado. Películas como Melodía cubana (The Cuban Love Song, W.S. Van Dyke, 1931) y La chica de Rio (Girl of the Rio, Herbert Brenon, 1932) eran tan 
ofensivas para Cuba y México que los gobiernos exigieron la prohibición de estas obras, pero los largometrajes rodados paralelamente o justo después del nacimiento de la Política de Buena Vecindad, como Volando a Río (Flying down to Rio, Thornton Freeland, 1933), Por unos ojos negros (In Caliente / Viva Seorita!, Lloyd Bacon, 1935), Rumba (Rumba, Marion Gering, 1935) y Serenata argentina (Down Argentine Way, Irving Cummings, 1940), también empleaban algunos de los estereotipos archiconocidos (Sadlier, 2012:37). Los ritmos latinos, la extrema sensualidad y el estilo de vida despreocupado eran los rasgos característicos que aparecían asociados con los personajes latinoamericanos de estas películas. En la mayoría de los casos, sobre todo en las obras hechas tras el cambio de actitud planteado por el presidente Roosevelt en 1933, estos clichés no tenían raíces malévolas, solo se mantenía en la superficie la caracterización simplificada de los pueblos de la región. Mediante estos filmes, Hollywood llegó a ser un cierto tipo de etnógrafo de las sociedades latinoamericanas: los cineastas estadounidenses definían (y luego redefinían) los rasgos característicos del "otro" y su propio acercamiento hacia los pueblos, todavía exóticos según este ideario fílmico, que luego entró en la memoria colectiva (López, 1993:67-70). Este enjuiciamiento no se podía desvincular de la memoria del legado colonial, conservando la mirada y apreciación europeas (y exclusivamente blancas) decimonónicas, incluso si se hacía esfuerzos para librarse de los lugares comunes anquilosados y obsoletos. Tanto en América del Norte como en Central y del Sur, los espectadores podían ver en el cine solo la versión hollywoodiense de los latinoamericanos.

A lo largo de la década de los 30 y 40, cada vez más personajes latinoamericanos aparecieron en las películas de las productoras cinematográficas, como MGM y $\mathrm{RKO}$, encarnados por actores hispanohablantes. No solo actores, cantantes y bailarines desconocidos sino las grandes estrellas del cine latinoamericano, como Dolores del Río de México y Desi Arnaz de Cuba, e incluso varios españoles fueron alistados durante los años de la Política de Buena Vecindad para dar vida a personajes latinoamericanos en la pantalla. Actores y actrices mexicanos, brasileños, argentinos y cubanos llegaron a Hollywood para interpretar papeles latinoamericanos, pero los directores y productores no prestaban atención a su verdadero origen: era común que un mexicano interpretara el papel de un argentino, un cubano el de un peruano, incluso brasileños aparecieron como mexicanos, sin prestar atención a las diferencias en la lengua o en el dialecto. Algunos de ellos ya habían trabajado en Hollywood en los años 20, cuando las dobles versiones (la versión en español de una película estadounidense rodada 
en el estudio paralelamente con la original, pero generalmente con un equipo diferente) estaban en su apogeo, pero la llamada "guerra de acentos", la indignación mundial por la despreocupación lingüística causó enormes problemas (Lénárt, 2013). Sin embargo, a lo largo de los años 40 los actores latinoamericanos seguían interpretando papeles latinos, sin tomar en cuenta su verdadero origen. En su empeño por acercarse a una autenticidad más prudente, las productoras contrataron a asesores latinoamericanos, incluso consultaron a políticos y consules de los países en cuestión, procurando esquivar la representación falsa de los personajes. Entrando en la década de los 40, cuando la Política de Buena Vecindad cobró su máxima fuerza, en algunos casos la productora retiró una película del programa o, en la fase de la posproducción, prohibió su estreno, si el modo de representación de un latino resultó discutible (Sadlier, 2012:40-41).

Aunque la División participó en la financiación de estas películas, de su rodaje se encargaron los grandes estudios o algunas productoras independientes, de ahí que los objetivos (en gran parte propagandísticos) de la nueva política de Roosevelt no podía prevalecer con exclusividad, la visión personal y la mirada subjetiva de los cineastas añadieron un componente adicional con el que las obras podían adquirir un verdadero valor artístico-cinematográfico. Desde luego, la OIAA y su División Cinematográfica mantenían bajo tutela las producciones en las que invertían y que, al fin y al cabo, tenían como meta principal cumplir con los propósitos político-culturales del gobierno estadounidense concernientes a América Latina.

Uno de los grandes logros de esta División cinematográfica se llevó a cabo a comienzos de los años 1940. Whitney propuso a Walt Disney un viaje a América Latina con el fin de profundizar la dimensión cultural de la Política de Buena Vecindad. Era importante, porque -según Whitney- el elevado número de inmigrantes italianos y alemanes en América del Sur aumentó la simpatía hacia los poderes del Eje. Aunque los EE. UU. todavía no era un país beligerante, pero quería frenar el avance del nazismo y fascismo en el continente. Disney primero rechazó el encargo, porque no quería participar en una misión meramente protocolaria y propagandística; no obstante, cuando surgió la posibilidad de rodar algunas películas durante el viaje, cambió de opinión. Tras contratar a un equipo de profesionales (director, dibujante, guionistas, compositor y también asesores que conocían la región), emprendieron el viaje. Pretendían adquirir experiencia personal y directa sobre la flora y la fauna, la costa, la selva las tradiciones y la sociedad para que los filmes fueran auténticos. Disney era 
muy popular en América Latina en todas las capas de la sociedad, en Brasil el presidente Getulio Vargas incluso le ofreció una cena de gala. Durante su viaje por América del Sur (pero también visitaron México y Puerto Rico), Disney y su equipo recorrieron varios países y regiones, y el resultado fue una enorme cantidad de ideas, bosquejos, dibujos y guiones. La consecuencia cultural e interamericana de esta gira fue incluso más notable. Hasta la llegada de Disney, dentro del marco de la Política de Buena Vecindad, solo políticos y propagandistas llegaron a América Latina. Esta vez los visitó un artista conocido y elogiado a nivel internacional, que se interesaba por su región y sus costumbres. En vez de los cortometrajes planeados, Disney hizo dos películas animadas (Saludos Amigos y Los tres caballeros, estrenados en 1942 y en 1944, respectivamente) que granjearon gran éxito en todo el continente americano, desde Alaska hasta Argentina, creando un verdadero puente entre las diferentes partes de las Américas. En estos dos filmes los cineastas combinaron la imagen real con la animada, varias estrellas latinoamericanas (como la bailarina Carmen Molina) aparecieron junto al pato Donald y otras figuras animadas en las aventuras ambientadas en América Latina, utilizando el material filmado durante el viaje. Esta misión llevada a cabo por Walt Disney y su equipo tuvo frutos tanto propagandísticos como culturales, pavimentando el camino hacia nuevos proyectos de esta índole (Thomas, 1987:151-154; Watts, 2001:243-248).

La Política de Buena Vecindad reclamaba géneros cinematográficos que atraían al público en todas las partes del continente americano, sin descartar la posibilidad de que las obras fueran exportables incluso a Europa. Tomando en cuenta las preferencias del público en la década de los 1930, parecía que -al lado de los melodramas- sobre todo las comedias musicales agradaban a los espectadores. A lo largo de la historia de la cinematografía, este género -y también las películas de aventura - tenían la mayor fuerza para distraer la atención del público y sumergirlo en el mundo de la fantasía. En estas obras el cabaret servía como el lugar por excelencia de la interacción social civilizada, y también como una metáfora del encuentro de todos los pueblos y sociedades del continente americano. Aunque esta visión del cabaret provenía de un punto de vista estadounidense, llegó a ser generalizada en las Américas, un tropo aceptado de las nuevas relaciones interamericanas. El ciclo de este tipo de obras comenzó justo en el año de la proclamación de la nueva política de Roosevelt en 1933, con la musical romántica Volando a Rio (Flying Down to Rio, Thornton Freeland) mencionada más arriba. El film salió del taller de la productora RKO que participaba de manera activa en la representación y defensa de los intereses políticos y finan- 
América Latina según Whitney y Disney. El cine interamericano de la Política de Buena Vecindad en los años 1930 y 40

cieros de los Estados Unidos. Con la mexicana Dolores del Río como protagonista, en papeles secundarios aparecieron también, por primera vez juntos, la famosa pareja Fred Astaire y Ginger Rogers. La trama simboliza una utopía hemisférica, aunque con fines imperialistas estadounidenses, incluyendo el crisol de antiguas ideologías -antes representadas por intelectuales latinoamericanos como Simón Bolívar, Domingo Faustino Sarmiento y José Martí- y dando forma a un pluralismo transnacional en la región. La obra comienza en los EE. UU., pero los protagonistas pronto llegan a Brasil, para que el público recibiera una nueva visión, un cierto tipo de reeducación sobre este lugar. Aunque la ambientación se concreta en este país, Brasil recibe aquí un significado mucho más amplio, granjea una interpretación generalizada que proyecta su validez a toda América Latina. En el nuevo concierto internacional, los latinoamericanos eran un pueblo amigable y generalmente de confianza, si bien todavía estaban presentes algunos estereotipos. Volando a Rio fue un punto de inflexión en la historia de las relaciones cinematográficas interamericanas, con esta obra se introdujeron los primeros elementos que modificaron la actitud estadounidense hacia América Latina. Desde luego, las causas de esta metamorfosis no eran meramente altruistas y desinteresadas, sino tenían fundamentos políticos y propagandísticos con el fin de servir el objetivo recién formulado del presidente Roosevelt (Pérez Melgosa, 2012:17-40). Ya que la Oficina para la Coordinación de Relaciones Comerciales y Culturales de las Repúblicas Americanas (la primera variante de la OIAA) todavía no existía, la obra del realizador Thornton Freeland fue un pionero en el sendero que conducía hacia el replanteamiento de las relaciones interamericanas. Este esquema seguía estando presente incluso en los años 40 con títulos como el ya mencionado Serenata argentina (Down Argentine Way, Irving Cummings, 1940) y Panamericana (Panamericana, John H. Auer, 1945), pero también hizo acto de presencia en los largometrajes mexicanos La liga de las canciones (Chano Urueta, 1941) y Calabacitas tiernas (Gilberto Martínez Solares, 1949), demostrando el aspecto deseado del panamericanismo (Pérez Melgosa, 2012:42).

\section{La importancia del nuevo acercamiento hacia América Latina}

A la hora de evaluar el éxito del aspecto cultural (más precisamente, en este caso, cinematográfico) de la Política de Buena Vecindad, no podemos desvincularlo de los objetivos principales de la política exterior estadounidense de la época. El mejoramiento de las relaciones interamericanas tenía dos propósitos. 
Por un lado, la meta impulsada por la realidad política, es decir, los acontecimientos europeos que amenazaban también el continente americano. Por otro lado, solo pocos años habían transcurrido desde el estallido de la crisis mundial de 1929 y los EE. UU. necesitaba una relación armónica con todas las regiones de las Américas para que pudiera salvaguardar sus antiguos mercados y, además, generar nuevos. Para alcanzar esto, hacía falta granjearse la simpatía y la confianza de los países de América Latina y del Caribe. En el terreno sociopolítico y económico, la nueva actitud tenía sus logros perfectamente visibles. A nivel cultural, la nueva política cinematográfica interamericana -aunque conservando las huellas evidentes de los estereotipos utilizados en la representación fílmica de los latinoamericanos- intentó contribuir al conocimiento mutuo de las diferentes naciones americanas. Las películas de buena vecindad de Hollywood con ambientación y temas o personajes latinoamericanos servían también como instrumentos de propaganda, mediante los cuales los valores y el estilo de vida de los Estados Unidos tenían la oportunidad de hacerse conocidos e incluso atractivos en todos los países del continente. Asimismo, había que plasmar una imagen positiva sobre América Latina a través del cine para justificar la Política de Buena Vecindad ante la sociedad estadounidense, paralelamente con el desmantelamiento de los antiguos esetereotipos, también configurados por el antiguo Hollywood. Esta nueva política tenía sus triunfos, aunque solo a corto y medio plazo. Después de la conclusión de la Segunda Guerra Mundial, se enfrentaban dos superpotencias en el periodo de la Guerra Fría: los Estados Unidos y la Unión Soviética. Conforme a las exigencias del nuevo concierto internacional, los EE. UU. modificó su política internacional y, por consiguiente, se vio obligado a replantear su actitud hacia los países extranjeros. Esta transformación llevó consigo la reevaluación de la Política de Buena Vecindad, ponderando las ventajas y desventajas que esta postura interamericana del presidente Roosevelt había traído en los años 1930 y 1940. En la nueva situación internacional, el objetivo principal de la Casa Blanca era proteger el hemisferio occidental de la influencia soviética a cualquier precio. Estos cambios eran contradictorios al principio fundamental de la no intervención, proclamada más de 15 años atrás, y dieron lugar a una nueva ola de injerencias estadounidenses en los asuntos de América Latina. Desde luego, en las décadas subsiguientes la cinematografía -junto con el poder político y económico ejercido sobre la sociedad nacional y extranjera por las productoras de Hollywood- volvería a entrar en el servicio de la política interior y exterior de los Estados Unidos de América. 
América Latina según Whitney y Disney. El cine interamericano de la Política de Buena Vecindad en los años 1930 y 40

\section{Bibliografía}

Benamou, Catherine L. 2007. It's All True: Orson Welles's Pan-American Odyssey. Berkeley: University of California Press.

Coatsworth, John H. 2005. "United States Interventions" ReVista. Harvard Review of Latin America, Summer 2005. Fecha de consulta: 28 de enero de 2018. Asequible en: http://revista.drclas.harvard.edu/book/united-states-interventions

Cramer, Gisela - Prutsch, Ursula. 2006. "Nelson A. Rockefeller's Office of Inter-American Affairs (1940-1946) and Record Group 229" Hispanic American Historical Review, 86/4.

Danticat, Edwidge. 28 de julio de 2015. "The Long Legacy of Occupation in Haiti" The New Yorker. Fecha de consulta: 28 de enero de 2018. Asequible en: https://www.newyorker.com/news/news-desk/haiti-us-occupation-hundredyear-anniversary

Jarvinen, Lisa - Peredo Castro, Francisco. 2011. "German Attempts to Penetrate the Spanish-Speaking Film Markets" Vande Winkel, Roel - Welch, David (eds.). 2011. Cinema and the Swastika: The International Expansion of Third Reich Cinema. Basingstoke - New York: Palgrave Macmillan.

Lénárt, András. 2013. "Hispanic Hollywood. Spanish-Language American Films in the 1920s and 1930s" Americana. E-Journal of American Studies in Hungary. IX/ 2. Fall 2013.

López, Ana M. 1993. "Are All Latins from Manhattan? Hollywood, Ethnography, and Cultural Colonialism" King, John - López, Ana M. Alvarado, Manuel (eds.). 1993. Mediating Two Worlds: Cinematic Encounters in the Americas. London: British Film Institute.

Moral Roncal, Antonio Manuel. 2003. Cuba ante la guerra civil española: la acción diplomática de Ramón Estalella. Madrid: Biblioteca Nueva.

Pérez Melgosa, Adrián. 2012. Cinema and Inter-American Relations. Tracking Transnational Affect. New York - London: Routledge.

Rankin, Mónica A. 2009. ¡México, la Patria! Propaganda and Production during World $W$ ar II. Lincoln \& London: University of Nebraska Press.

Sadlier, Darlene J. 2012. Americans All. Good Neighbor Cultural Diplomacy in World W ar II. Austin: University of Texas Press. 


\section{András Lénárt}

Selser, Gregorio. 2001. Cronología de las intervenciones extranjeras en América Latina. Tomo III. Universidad Nacional Autónoma de México.

Thomas, Bob. 1987. Walt Disney. Egy találékony amerikai. Budapest: Könyvért.

Watts, Steven. 2001. The Magic Kingdom. Walt Disney and the American Way of Life. Columbia and London: University of Missouri Press. 